\title{
Study of Multi-Resident Location Tracking Service Model Based on Context Information
}

\author{
Jeong Chang Won ${ }^{+} \cdot$ Ko Kwang Man ${ }^{++} \cdot$ Joo Su Chong ${ }^{+++}$
}

\begin{abstract}
In recent years, because of the development of ubiquitous technology in healthcare research is actively progress. Especially, healthcare service area is change to home for the elderly or patients from hospital. The technology to identify residents in a home is crucial for smart home application services. However, existing researches for resident identification have several problems. In this case, residents are needed to attach of various sensors on their body. Also relating private life, it is difficult to apply to resident's environment.

In this paper, we used constraint-free sensor and unconscious sensor to solve these problems and we limited using of sensor and indoor environment in the way of working economical price systems. The way of multi-resident identification using only these limited sensors, we selected elements of personal identifications and suggested the methods in giving the weight to apply these elements to systems. And we designed the SABA mechanism to tract their location and identify the residents. It mechanism can distinguish residents through the sensors located each space and can finally identify them by using the records of their behaviors occurred before. And we applied the mechanism designed for applications to approve this location tracking system. We verified to the location tracking system performance according to the scenario.
\end{abstract}

Keywords: u-Home Environments, Multi User Identification, Indoor Location Tracing, Tracking Service Model, Healthcare Home Service

\section{상황정보 기반의 다중 거주자 위치 추적 서비스에 관한 연구}

\author{
정 창 원 $^{\dagger} \cdot$ 고 광 만 ${ }^{\dagger+} \cdot$ 주 수 종 ${ }^{+\dagger}$
}

\begin{abstract}
요 약
최근, 유비쿼터스 기술의 발전으로 인하여 헬스케어 연구가 활발하게 진행되고 있다. 특히, 헬스케어 서비스 영역은 독거노인 또는 환자를 위해 병원에서 가정으로 변화하고 있다. 홈에서 거주자를 식별하는 기술은 스마트 홈 응용 서비스에 매우 중요하다. 그러나, 기존의 거주자 식 별연구들은 여러 문제점을 갖고 있다. 몸에 다양한 센서를 부착해야 하며, 개인 프라이버시와 관련되어 거주자 환경에 적용하는데 문제점들이 따르고 있다.

본 논문에서는 이러한 문제점들을 해결하기 위해 무구속, 무자각을 지향하는 센서들의 사용과 저비용으로 시스템을 구현하기 위한 방법으로 써 실내 환경 및 센서의 사용을 제한하였다. 이렇게 제한된 센서들만을 이용하여 거주자를 식별하기 위한 방법으로 개인을 식별할 수 있는 요 소들을 추출하고 이러한 요소들을 시스템에 적용하기 위해 가중치를 부여하는 방법을 이용하였다. 그리고 거주자를 식별하고 위치를 추적하기 위한 $\mathrm{SABA}$ 메커니즘을 설계하였다. $\mathrm{SABA}$ 메커니즘은 각 공간별로 배치된 센서들을 통해 거주자를 식별하고 거주자의 행위에 의해 발생한 이전 이벤트들의 기록들을 활용하여 최종적으로 거주자를 식별하여 개별 거주자의 위치를 추적한다. 그리고 본 위치 추적 시스템의 수행성을 검증하기 위해 구현한 응용에 설계된 메커니즘을 적용하고 시나리오를 통해 위치 추적 시스템의 성능을 검증하였다.
\end{abstract}

키워드 : u-홈 환경, 다중 거주자 식별, 실내 위치추적, 추적 서비스 모델, 헬스케어 홈서비스

\section{1. 서 론}

※ 이 논문은 2013학년도 원광대학교의 교비 지원에 의해서 수행됨.

† 정 회 원: 원광대학교 리서치펠로우 연구교수

†† 종신회원 : 상지대학교 컴퓨터정보공학부 교수

†\#和 회 원 : 원광대학교 컴퓨터공학과 교수

Manuscript Received : March 17, 2014

First Revision : April 1, 2014

Accepted: April 1, 2014

* Corresponding Author:Joo Su Chong(scjoo@wku.ac.kr)
최근 홈 환경을 기반으로 위치 추적 기술에 관한 연구가 활발하게 진행되고 있다 $[1,2]$. 대표적인 실내 위치 추적기술 은 태그를 이용하거나 위치 센서 또는 카메라를 이용하여 거주자의 식별과 움직임을 통해 집안 내 활동 상황을 주기 
적으로 파악하여 응급상황에 신속하게 조치를 취할 수 있는 서비스가 주류를 이루고 있다. 이러한 서비스를 제공하기 위한 인프라적인 측면에서 점차 센서 네트워크를 기반으로 연구가 진행되고 있다[3].

특히, 이러한 실내 위치 추적기술은 $\mathrm{u}^{-}$헬스케어에 대한 요구사항으로 사회적인 배경을 갖고 있다. 현재 미국, 일본, 독일, 영국을 비롯한 선진국들에서는 1990년대에 65세 이상 의 노인들이 전체 인구에서 $7 \%$ 가 넘는 고령화 사회에 접어 들었으며 우리나라도 2000년을 기점으로 고령화 사회에 진 입한 실정이다[4]. 또한, 대부분의 고령자들이나 질병을 가진 사람들은 주로 자신의 집에 있기를 원하고 심지어 자신의 상태가 좋지 않거나 집으로부터 자신의 안전을 보장 받을 수 없다는 것을 인지하였을지라도 집에 있기를 원한다. 한 국가적 차원의 조사[5]에서 연구자들은 응답자의 $71 \%$ 가 가 능한 한 자신의 현재 거주하는 집에 있기를 강하게 희망했 으며 $12 \%$ 정도만 그렇지 않은 결과를 얻었다. 따라서 집에 주로 거주하게 되는 노령자들의 건강 복지를 위한 방안으로 집안의 거주 환경과 거주자의 신체적 상태를 감시할 수 있 는 환경 및 생체 신호 센서를 설치하여 고령자의 안전 및 삶의 질을 개선할 수 있는 헬스 스마트 홈 기술이 대두되고 있다[6, 7]. 실내 위치 기반 연구에서 명확한 식별을 위해 사 용하는 태그나 배지 등과 같은 부착 센서를 이용한 기술은 실제 활용 면에서 부착하지 않으면 소용없는 문제점을 갖고 있다. 또한 카메라 인식 기술은 다수의 사용자를 식별하여 개별적인 서비스에 적용할 수 있지만 고가의 카메라와 사용 자의 개인 사생활 침해와 같은 문제점을 갖고 있어 시스템 을 보편화기가 쉽지 않다.

따라서, 본 연구에서는 이와 같은 기존 거주자의 식별 문 제점들을 해결한 다중 거주자의 식별과 위치 추적 서비스 모델을 제안한다.

본 논문의 구성은 다음과 같다. 2 장에서는 관련연구로 대 표적인 거주자 식별방법 및 제안한 방법과의 차이점에 대해 설명하고, 3 장에서는 본 논문에서 제안하는 거주자의 식별 방법에 대해서 기술한다. 4장에서는 다중 거주자의 위치추 적 시스템 환경과 상황정보 기반의 거주자 위치 추적 서비 스 모델과 시나리오 및 분석 결과를 보인다. 마지막으로 5 장에서는 결론 및 향후 연구 내용으로 끝맺고자 한다.

\section{2. 관련 연구}

스마트 홈에서 거주자를 식별하거나 추적하기 위한 연구 들은 오래전부터 꾸준히 진행되고 있다. 본 장에서는 지금 까지 연구되어온 대표적인 방법들과 제안한 연구와의 차이 를 살펴본다.

\section{1 기존의 거주자 식별 방법}

태그와 트랙을 이용하는 방법은 각 개인별 거주자에 유일 하게 식별할 수 있는 장치를 위치시킴으로써 동작하게 된다. 이 방법은 거의 20년 가까이 액티브 뱃지(Active Badge) 시
스템으로 사용되었다[8]. 우드만에 의해 제안된 단순 지역화 (Pedestrian Localization)시스템은 추가적인 인프라가 아닌 넓 은 사무용 건물에서 몸에 착용하는 관성 센서(Inertial Sensor) 를 이용한다. 좀 더 최근에는 매우 적은 인프라 비용을 요 구하는 혁신적인 추적 솔루션을 제안하고 있다. 그러나 이 러한 방법은 거주자가 장치를 몸에 항상 소지해야 하는 단 점이 있다.

카메라, 마이크로폰, ASP(Audio Signal Processing)을 이 용한 방법[9, 10]은 비전 알고리즘(Vision Algorithms)을 높 은 통신 대역폭을 사용하며 계산 비용이 높지만 정확성을 갖는다. 그러나 WellAware 회사와 인텔(Intel)소속의 연구자 의 연구는 다수의 거주자들을 식별하는 데 카메라나 마이크 로폰 센서를 사용함으로써 프라이버시 침해 문제가 발생된 다. 그렇기 때문에 이 방법은 짧은 시간의 상황들을 요구거 나 높은 정확성이 요구되는 환경 그리고 장시간 모니터링 되지 않는 환경에 가장 적합하다.

모션 센서, 스위치 센서, 거주자 활동을 이용한 방법은 거 주자의 위치와 활동들을 추적하거나 식별하기 위해 제안한 방법으로 Markov 상태변화와 태그와 트랙 방법을 사용하여 얻은 짧은 시간의 연습 데이터로부터 학습하는 방법을 사용 하는 센서기반의 Particle Filter의 사용을 제안하였다[11]. 이 방법의 장점은 단순한 Single-Pixel 센서들이 비교적 비 용이 적고 쉽게 설치가능하며 거주자에게 불편을 주거나 프 라이버시를 침해하지 않는다. 하지만 한 주 동안 실험에서 3 명의 거주자를 추적하는 데 $70 \%$ 의 정확성을 얻었다.

Active Floor와 Smart Floor을 이용한 방법[12]은 거주자 집단을 대상으로 한 연구로 집단 내에 있는 다양한 개개인을 식별하기 위해 Force Plate Signal을 사용한다. 해당 연구에 서 사용하는 걸음걸이 분석(Gait Analysis)은 설치된 Floor들 로부터 개개인을 구분하기 위해 사용된다. 이러한 SinglePixel Mass-Based 식별 방법은 거주자를 불편하게 하지 않 고 프라이버시를 침해하지 않는 장점을 갖는다. 하지만 Force Plates와 Smart Floors는 설치 시 주의가 요구되며 정확성 이 높은 Force Plates는 고가의 구축비용이 요구된다.

높이를 이용한 방법은 운전자의 면허증 또는 경찰기록에 사용되며 집단을 대상으로 한 개개인 구분에는 사용될 수 없다. 한 연구[13]에서는 침해성이 있는 비디오카메라를 이 용하여 높이를 식별하고 Nishida 등[14]은 초음속 레이더 (Ultrasonic Radar) 시스템으로 아주 정확한 위치 추적을 수 행하기 위해 초음속 장치(Ultrasonic Devices)를 촘촘히 구 성하여 천장에 설치하는 것을 제안하였다. 그러나 이런 시 스템은 개인들을 구별하거나 식별하기 위해서는 상당한 배 치 노력을 요구된다. Jenkins 등[15]은 출입구 위에 적외선 이나 초음속 거리 탐지기(Ultrasonic Distance Detectors)를 놓는 것을 제안하였다. 하지만 이러한 높이 센서는 실내에 서 걸어다니는 거주자를 대상으로 한 정확성을 위한 경험적 인 평가가 부족하다. 
Table 1. A comparison of identification and tracking methods

\begin{tabular}{c|c|c|c|c|c|c}
\hline 방법들 & $\begin{array}{c}\text { 다중 } \\
\text { 거주자 } \\
\text { 추적 }\end{array}$ & 이동장치 & 사생활침해 & 정확성 & 편의성 & $\begin{array}{c}\text { 설치 } \\
\text { 난해성 }\end{array}$ \\
\hline $\begin{array}{c}\text { 태크와 트랙 } \\
\text { 이용 }\end{array}$ & 가능 & 사용 & 없음 & 높음 & 낮음 & 낮음 \\
\hline $\begin{array}{c}\text { 카메라, } \\
\text { 마이크로폰, } \\
\text { ASP }\end{array}$ & 가능 & 비사용 & 있음 & 높음 & 높음 & 낮음 \\
\hline $\begin{array}{c}\text { 모션, } \\
\text { 스위치, } \\
\text { 거주활동 }\end{array}$ & 가능 & 비사용 & 없음 & 보통 & 높음 & 낮음 \\
\hline $\begin{array}{c}\text { Active } \\
\text { Floor와 } \\
\text { Smart } \\
\text { Floor }\end{array}$ & 가능 & 비사용 & 없음 & 보통 & 높음 & 높음 \\
\hline Height & 가능 & 비사용 & 없음 & - & 높음 & 보통 \\
\hline 제안 방법 & 가능 & 비사용 & 없음 & 보통 & 높음 & 낮음 \\
\hline
\end{tabular}

\section{2 기존 연구와 차이점}

기존의 실내 거주자들의 식별 또는 추적에 관한 연구들은 각각의 센싱 방법에 따라 다양한 특징을 갖고 있다. 각 방 법들에서 사용되는 센서들은 몸에 부착하거나 지녀야 하는 불편함을 초래하기도 하며 개인 프라이버시와 같은 사생활 침해 문제점을 갖는다. 또한 어떤 센서들은 비교적 정확성 은 높지만 인프라 구축비용이 요구되며 실내에 설치하는 데 어려움을 갖고 있다. 본 논문에서 제안하는 위치추적 방법 은 최소한의 센서들과 생체 인식 센서(Biometric Sensor)들 을 포함하고 있다. 본 연구는 이러한 추가되는 센서를 대체 하는 방법으로 다양한 식별 요소들을 이용하는 새로운 메커 니즘을 제안한다. Table 1은 기존 연구들과 제안한 연구의 비교분석한 결과를 보인다.

\section{3. 상황정보 기반의 거주자 식별 방법}

본 장에서는 제안하는 상황정보 기반의 거주자 식별 방법 에 대해 기술한다. 상황정보는 먼저 가정 내의 영역별 거주 자의 행위를 파악할 수 있도록 분류하고, 이를 기반으로 거 주자를 식별하고 가중치와 누적치를 이용하여 한 사람 이상 의 거주자를 추적하도록 하였다.

\section{1 공간별 영역 분류}

본 논문에서 제안하는 상황정보는 공간별 영역 상에서 발 생할 수 있는 상황을 기반으로 한다. 공간별 영역은 안방, 화장실, 주방, 현관, 거실로 분류하였다. 각각의 공간은 본 논문의 목적에 맞게 최소한의 센서만을 이용하도록 하고 연 구의 특성에 맞게 요구되는 사용도구들을 사용함으로써 이 벤트를 발생시킨다. 이와 같은 실내 환경을 구성하는 각 센 서들의 역할은 Table 2 와 같다.

\section{2 거주자 식별}

거주자의 상황 인식하기 위한 기준은 시간, 장소, 도구, 기타사항을 사용하였고 이를 기반으로 발생하는 이벤트를
Table 2. Indoor sensors and roles

\begin{tabular}{c|c|l}
\hline 분류 & 센서 & \multicolumn{1}{c}{ 역할 } \\
\hline \multirow{3}{*}{ 환경정보센서 } & 온도센서 & 실내 온도 정보 획득 \\
\cline { 2 - 3 } & 조도센서 & 실내 조도 정보 획득 \\
\cline { 2 - 3 } & 습도센서 & 실내 습도 정보 획득 \\
\hline \multirow{3}{*}{ 위치정보센서 } & $\mathrm{ON} / \mathrm{OFF}$ 센서 & $\begin{array}{l}\text { 식탁 의자, 소파, 침대, 비 데로부터 } \\
\text { 거주자 감지 }\end{array}$ \\
\cline { 2 - 3 } & 근접센서 & $\begin{array}{l}\mathrm{TV}, \text { 세면대, 싱크대, 가스레인지, } \\
\text { 냉장고, 비데, 세탁기로부터 거주자 감지 }\end{array}$ \\
\hline \multirow{2}{*}{ 상태정보센서 } & 도어센서 & 문의 열림/닫힘 여부 정보 획득 \\
\hline \multirow{3}{*}{ 신체정보센서동감지센서 } & 거주자의 활동여부 정보 획득 \\
\cline { 2 - 4 } & 하중센서 & $\begin{array}{l}\text { 세면대 바닥으로부터 거주자의 무게 } \\
\text { 정보 회득 }\end{array}$ \\
\cline { 2 - 3 } & 거리센서 & 현관문으로부터 거주자의 키 정보 획득 \\
\hline
\end{tabular}

분석한 결과 Table 3 에 정의된 상황과 기준을 모두 만족하 는 경우 올바른 거주자의 상황으로 처리하도록 한다. 첫째 로 시간은 다수의 거주자들 중 어느 한 명에만 속할 수 있 는 개인 스케줄에 해당하는 시간과 모두 동일하게 사용되는 시간(예를 들어, 식사 등)은 '설정 시'라 하였고 이외 가변적 으로 일어날 수 있는 상황의 시간은 '임의’라 하였다. 장소는 앞서 물리적인 환경에서 제시된 공간들을 나타낸다. 둘째로 도구는 문을 포함하여 공간을 이루고 있는 가전기기와 가구 를 나타낸다. 셋째로 기타사항은 특이 사항으로 본 기준에 서는 취침 시 조도 값의 변화만을 나타낸다.

Table 3. The value associated with the context

\begin{tabular}{|c|c|c|c|c|}
\hline 상황 & 시간 & 장소 & 도구 & 기타사항 \\
\hline 외출 & 임의 & 현관 & 현 관문 & 없음 \\
\hline 귀가 & 임의 & 없음 & 현관문 & 없음 \\
\hline 식사 & 설정 시 & 주방 & 식탁의자 & 없음 \\
\hline 세면 & $\begin{array}{c}\text { 설정 시 } \\
\text { 또는 임의 }\end{array}$ & 화장실 & 세면대 & 없음 \\
\hline $\mathrm{TV}$ 시청 & 임의 & 거실 & $\mathrm{TV}$, 소파 & 없음 \\
\hline 여가 & 설정 시 & 거실 또는 실외 & 없음 & 없음 \\
\hline 취침 & 설정 시 & 안방 & 침대 & 낮은 조도 값 \\
\hline $\begin{array}{l}\text { 화장실 } \\
\text { 이용 }\end{array}$ & 임의 & 화장실 & 비대 & 없음 \\
\hline 낮잠 & 설정 시 & 안방 & 침대 & 없음 \\
\hline 출근 & 설정 시 & 현관 & 현관문 & 없음 \\
\hline 이동 & 임의 & 모든 장소 & 없음 & 없음 \\
\hline 휴식 & 임의 & 거실 또는 안방 & 소파 또는 침대 & 없음 \\
\hline 주방일 & 설정 시 & 주방 & 주방도구 & 없음 \\
\hline
\end{tabular}

단일 홈 내에 거주하는 다중 거주자의 위치를 추적하기 위해선 거주자 개개인을 먼저 구분해낼 수 있어야 한다. 하 지만 무자각, 무구속을 지향하는 센서들만을 사용하여 개인 을 구분하는 데는 해당 거주자의 확실한 식별자로 사용할 수 있는 데이터를 얻을 수 없다. 이러한 문제를 해결하기 위해 본 논문에서는 거주자 개개인을 식별할 수 있는 즉, 개인만이 가질 수 있는 유일한 요소들 또는 다른 대상과 차 이를 갖는 요소들을 추출하여 이를 이용한 거주자의 개별 식별을 통해 위치를 추적하도록 하였다. 
Table 4는 관련연구를 통해 추출된 다양한 요소들 가운 데서 본 연구 환경에 적용될 수 있는 몇 가지 선별되어진 요소들이며 구현상에서 그대로 적용하도록 하였다.

Table 4. Residents identify factors

\begin{tabular}{c|c|c|c}
\hline 구분 & 항목 & \multicolumn{1}{|c}{ 요소 } \\
\hline \multicolumn{1}{c|}{ 객체 } & 신상정보 & 이름, 나이, 성별, 몸무게, 키 \\
\hline \multirow{3}{*}{ 패 } & 물 & 주방도구 & 가스레인지, 냉장고, 찬장, 싱크대, 세탁기 \\
\cline { 2 - 4 } & 선호위치 & 식탁의자, 소파 \\
\cline { 2 - 4 } & 논 & 역할 & 가사, 외업 \\
\cline { 2 - 4 } & 리 & 시간 & 취침, 낮잠, 외업, 식사, 주방일, 세면, 여가 \\
\hline
\end{tabular}

추출된 각각의 요소들은 모두 거주자를 식별하는 데 사용 하지만 이러한 요소들은 직접적인 연관성이 없으므로 연관 성을 갖도록 각각의 특징들을 비교해야 하는 식별과정 시간 이 길어질 수 있고, 원하지 않는 결과를 초래할 수 있다.

앞서 언급한 식별방법으로 얻어진 각각의 요소들에 연관 성과 의미를 부여하기 위한 방법으로 가중치를 이용하였다. Table 5는 가중치를 부여하게 된 경우와 이에 매핑한 가중 수치를 나타낸다.

Table 5. The value associated with the context

\begin{tabular}{|c|c|c|}
\hline 가중치 & 경 우 & 부가설명 \\
\hline 0 & -식별불가 & $\begin{array}{l}\text { 거주자가 다른 행위 없이 이동만 하는 } \\
\text { 경우 }\end{array}$ \\
\hline 30 & -주방도구의 사용 & 거주자의 역할이 가사인 경우 \\
\hline 50 & -선호위치의 이용 & 설정된 위치에 해당하는 거주자 \\
\hline 70 & -비데 올림 & 거주자의 성별이 남자 \\
\hline 100 & $\begin{array}{l}\text {-무게・키 감지 } \\
\text {-시간과 상황 일치 }\end{array}$ & $\begin{array}{l}\text { 설정된 무게와 키에 해당하는 거주자 } \\
\text { 거주자의 스케줄과 관련된 상황 }\end{array}$ \\
\hline
\end{tabular}

누적치는 거주자가 완전히 식별되지 않은 가중치인 0에서 100 까지의 가중치를 이벤트 발생 시마다 합한 수치를 의미 한다. 이러한 누적치는 거주자를 식별하는 과정에서 임시 거주자의 큐에 매달린 임시 결과에 기록되어 있는 가중치를 이용해 구해지며 별개로 저장소를 두고 기록하지 않는다. 결국 누적치는 거주자 식별 과정시마다 다시 구해지며 누적 치가 100 이상이 되는 경우 완전한 최종식별로 간주한다. 다음 Fig. 1은 가중치와 누적치에 의해 최종 식별되는 과정 을 보이고 있다.

\begin{tabular}{|c|c|c|c|c|c|}
\hline 이벤트 & 사용자 & 가중치 & 누적치 & 식별 & 최종식별 \\
\hline EVENT_8 & PA & 100 & 100 & o & 0 \\
\hline EVENT_7 & PA & 50 & 140 & 0 & 0 \\
\hline EVENT_6 & PB & 70 & 120 & o & 0 \\
\hline EVENT_5 & P? & 0 & & $\mathbf{x}$ & X \\
\hline EVENT_4 & PB & 50 & 50 & $\mathrm{x}$ & o \\
\hline EVENT_3 & PA & 30 & 90 & $\mathrm{x}$ & 0 \\
\hline EVENT_2 & PA & 30 & 60 & $\mathrm{x}$ & o \\
\hline EVENT_1 & PA & 30 & 30 & $\mathrm{X}$ & 0 \\
\hline
\end{tabular}

Fig. 1. The process of identifying residents
예를 들어, 거주자 $\mathrm{PA}$ 와 $\mathrm{PB}$ 가 실내에 존재한다고 가정할 때, 첫 이벤트인 이벤트1에서 예상되는 거주자가 PA로 임시 식별되었으며 이에 해당하는 가중치는 30이 부여되었다. 임 시 거주자 큐 $\mathrm{PA}$ 는 누적결과 30 이며 아직 식별되지 않은 상태이다. 이벤트2와 이벤트3에서도 마찬가지로 예상 거주 자 $\mathrm{PA}$ 의 임시 거주자 큐에 등록되고 각각 30 의 가중치를 갖고 누적치가 100 미만으로 여전히 식별되지 않은 상태이 다. 다음으로 이벤트4에서 예상되는 거주자가 $\mathrm{PB}$ 로 임시 식 별 되었고 가중치는 50으로 역시 아직 식별되지 않은 상태 이다. 이벤트5는 예상되는 거주자도 알 수 없는 상태이며 가중치는 0 이다. 이벤트 6 은 예상되는 거주자가 $\mathrm{PB}$ 이고 가중 치는 70 이다. 이때, 임시 거주자 큐 $\mathrm{PB}$ 에 등록된 임시 결과 들을 누적한 결과 120 이 되므로 식별로 처리하여 이전 임시 결과까지 $\mathrm{PB}$ 거주자로 최종 처리한다. 다음 이벤트7과 이벤 트8 과정도 동일하게 진행된다.

\section{3 공간분석과 역 분석(SABA) 메커니즘}

$\mathrm{SABA}$ (Space Analysis and Back Analysis) 메커니즘은 지금까지 설명한 상황, 가중치, 누적치 방법을 종합적으로 사용하여 설계한 메커니즘으로 공간 분석과 역 분석을 통하 여 거주자를 식별하는 방식을 취하도록 설계하였다.

먼저, 공간 분석은 다수의 거주자의 행위에 의해 발생한 무수한 이벤트들을 분석하기 위한 방법으로 사용되었다. (Fig. 2)는 이벤트들 중에서 존재하는 거주자의 수를 얻기 위한 과 정을 나타낸다. 모든 이벤트들의 수 즉, 센서의 수는 26개(조 도, 습도, 온도 제외)로 $32 \mathrm{bit} \mathrm{os}$ 에서 갖는 unsigned int형을 비트로 나타내면 총 32 (4byte * 8bit)bit로 32개의 자릿수를 넘지 않기 때문에 표현하기 쉽게 모든 이벤트들을 비트 형태 로 취하여 하나의 unsigned int형 메모리 공간으로 관리한다. 그리고 센서들은 Fig. 3과 같이 고유의 비트 형태의 값으로 정의함으로써 정의된 센서값들은 이벤트들이 담긴 메모리 공 간의 비트별 자릿수별로 1 대1 매치하도록 하였다.

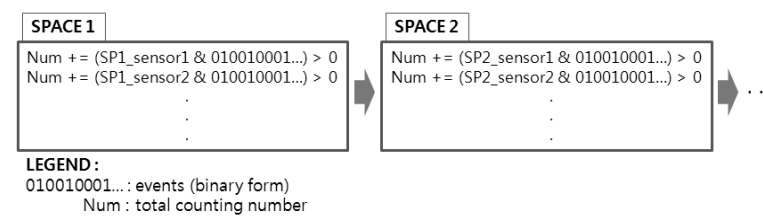

Fig. 2. The process for obtaining the number of residents

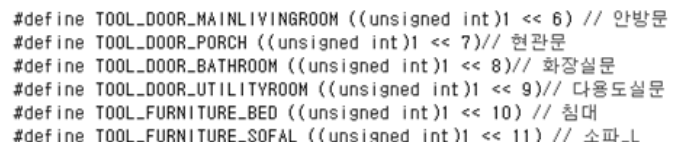

Fig. 3. Defined tools by bit position

이때, 각 공간별로 int형 메모리 공간에 담긴 이벤트들과 정의된 센서 값의 $\mathrm{AND}$ 연산을 통해서 0 보다 큰 경우를 비 교하면 해당 공간에서 발생한 이벤트임을 알 수 있어 해당 공간에 거주자가 있음을 알 수 있다. 하지만 이러한 분석의 경우 한 공간에서 거주자 한 명이 행위를 일으킬 때 1 개 이 상의 이벤트를 동시에 발생시키는 경우도 있으므로 두 명으 로 처리되지 않도록 하였다. 또한 공간 분석은 이벤트들이 


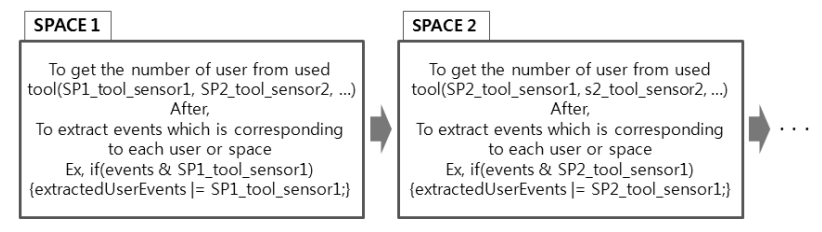

Fig. 4. The separation process events

다수의 거주자에 의해 생성된 경우 각 거주자의 행위별로 이벤트들을 분리할 때에도 사용하였다. Fig. 4는 각 공간에 서 이벤트를 분리하는 과정이다.

이벤트들을 분리 시 첫 번째로 수행되는 과정은 한 공간 상에 거주자 한 명이 존재할 수도 있고 다수가 존재할 수 있으므로 공간별로 존재하는 센서들(도구들-가전기기, 가구, 문) 중 사용된 센서들로부터 수집된 정보를 토대로 거주자 의 수를 파악한다. 그리고 거주자의 수에 맞게 관련 있는 이벤트들을 추출하여 추출된 이벤트들을 저장하기 위해 별 개의 메모리 공간에 저장한다. 다음으로 역 분석은 공간 분 석 과정을 모두 거친 후 거주자를 최종적으로 식별하기 위 한 방법으로 사용된다. 본 연구에서 역 분석은 이전의 상태 를 확인한 후 현재 상태와 비교하거나 이전의 상태를 모아 놓은 임시결과 큐를 이용하여 거주자를 식별하는 방법이다. 거주자의 이전 상태와 현재 상태를 비교하는 방법은 기본적 으로 거주자의 위치를 이용한다. 예로 들면, 현재 발생한 이 벤트를 분석한 결과 거주자의 위치가 안방이라고 가정하면 이전에 분석했던 결과 중 현재 거주자와의 위치가 안방으로 서로 동일한 경우 각각의 두 결과를 동일 거주자에 대한 결 과로 볼 수 있다. 다른 상황으로는 이전 결과 중 결과에 해 당하는 이동상황인 경우이다. 이 경우 현재 발생한 이벤트 들을 분석한 결과에 나타난 거주자의 위치와 이전 결과에서 이동상황 후 공간 위치를 비교하여 두 위치가 동일한 경우 동일한 거주자임을 알 수 있다. 마지막 상황으로는 예상되 는 거주자의 비교이다. 현재 가식별된 거주자와 이전에 가 식별되었던 거주자 중 동일한 거주자가 있다면 가식별된 거 주자이지만 시스템에 등록된 거주자의 정보에 의한 결과 이 므로 가식별 거주자와 실제 거주자를 어느 정도 일치시킬 수 있다. 그러므로 결국 이전의 가식별된 거주자 결과와 현 재 결과를 일치시킬 수 있다. 단, 지금까지의 상황에서 다른 거주자의 경우는 다른 공간상에 존재한다고 가정한다.

다음으로 임시결과 큐를 이용한 방법은 앞서 설명한 누적 치를 사용하는 방법이다. 임시결과 큐(누적치에서 설명한 임 시 거주자 큐와 동일)는 아직 완전히 식별되지 않은 이벤트 들의 가결과를 모아놓은 저장소로 이벤트 발생 시간별로 큐 형식에 맞게 저장하고 새로운 이벤트가 발생하면 큐의 처음 (가장 오래된 결과)부터 마지막(최근결과)까지 확인하여 누 적치를 구하는 데 사용된다. 이상의 방법들은 이벤트들에서 가거주자조차도 식별할 수 없는 가중치 0의 경우에도 현재 와 이전의 연관관계를 제공하여 거주자를 식별할 수 있다.

\section{4. 다중거주자 위치추적 서비스 모델기반 시스템}

\section{1 구현 환경}

본 논문에서 제안한 다중 거주자의 위치 추적을 위한 전

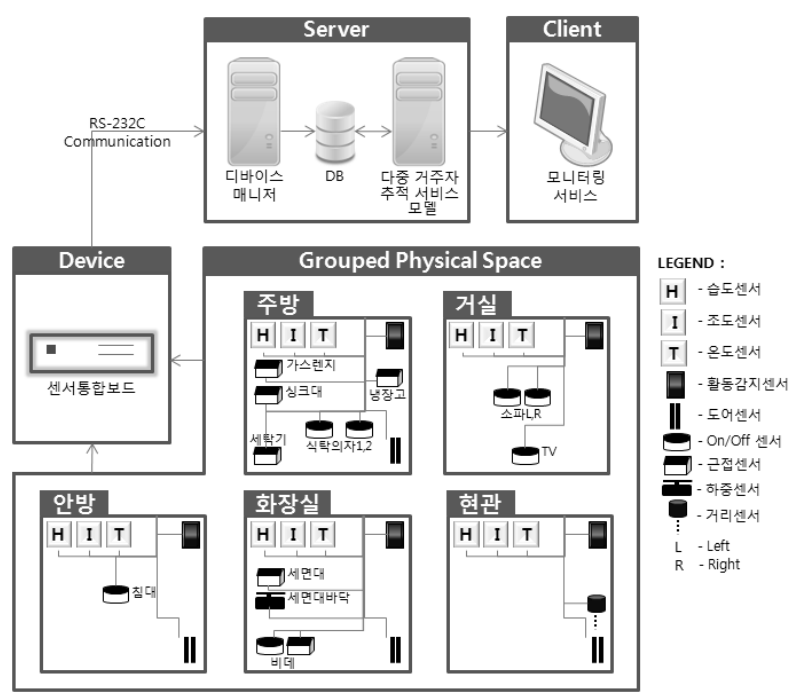

Fig. 5. The overall system configuration

체 시스템 구성은 다음 Fig. 5와 같다.

각각의 공간은 그룹별로 각 센서들이 거주자 위치를 편리 하게 추출할 수 있는 적재적소에 배치되어진다. 이러한 센 서들은 무작위로 데이터를 수집하기도 하며 센서마다 처리 후 생성하는 값의 형식이 일치하지 않기 때문에 이를 통합 적으로 관리하기 위한 디바이스가 존재한다. 디바이스는 데 이터를 하나로 통합하여 이를 고 수준의 정보로 처리하기 위한 서버로 전송하게 된다. 서버는 저 수준 데이터를 처리 하기 위해 존재하며 이를 위한 응용들로 구성된다. 마지막 으로 서버에서 처리된 결과를 보여주기 위한 클라이언트가 존재 한다.

거주자의 위치를 추적하는 데 사용되는 이벤트들은 시스 템의 제일 하단에 존재하는 센서들에 의해 생성된다. 각각 의 센서들은 이를 통합 - 관리하는 센서통합보드와 연결되어 센싱한 데이터를 전달한다. 센서통합보드는 수집된 데이터 들을 하나로 모으는 통합과정을 거치며 규칙적으로 형식화 된 패킷을 생성하는 역할을 수행한다. 그리고 시리얼 포트 를 통해 서버와 연결되어 $\mathrm{RS}-232 \mathrm{C}$ 통신 절차를 걸쳐서 서 버로 패킷을 송신한다. 패킷을 수신하기 위한 디바이스 매 니저가 존재하며 디바이스 매니저는 서버와 센서통합보드와 연결을 구성하고 주기적으로 데이터를 수신 후 데이터가 올 바른 형식으로 수신되었는지를 확인한다. 데이터가 올바른 형식이 아닌 경우 이를 버리고 다시 수신하며 올바른 형식 을 가진 데이터를 수신한 경우에만 큐 저장소로 보낸다. 큐 저장소에 채워진 데이터들은 큐 처리기에 의해 큐 저장소에 데이터가 있을 때마다 데이터를 하나씩 가져와 다음 응용에 전달하기 위해 데이터베이스에 데이터를 저장한다. 이후 위 치추적서비스모델에서는 저장된 데이터를 읽어와 데이터 분 석을 시작한다. 먼저 복합이벤트를 분석하여 거주자별로 분 리하고 분리된 복합이벤트들을 다시 분석과정을 거쳐 거주 자 식별 과정에 들어간다. 식별 과정에서 얻어진 결과들은 완전 식별이 되기까지 임시결과큐에 보관되며 식별이 완료 되면 데이터베이스에 기록한다. 이렇게 최종적으로 기록된 결과를 이용하여 마지막 과정인 뷰 처리 과정을 거쳐 클라 이언트인 모니터링서비스를 수행한다. 
센서통합보드에 의해 센서들로부터 얻어진 데이터들이 하 나의 패킷 데이터로 재생산 되면 이를 처리하기 위해 구현 한 디바이스 매니저가 서버에 존재하는 자원들을 이용하여 최종적으로 데이터베이스에 저장한다. 디바이스 매니저는 처음 Connector에 의해 센서통합보드와의 연결과 DBMS와 의 연결 과정을 거치며 연결이 성사되면 본격적인 동작에 들어간다. 센서통합보드는 연결이 완료되면 디바이스 매니 저로 주기적으로 데이터를 전송하며 이를 Receiver가 임의 로 정한 주기인 1 초에 한 번씩 송신하게 된다. 이 과정에서 서로의 주기가 일치하지 않음으로 인한 원본데이터와의 불 일치가 발생하게 되므로 수신한 데이터가 정해진 형식에 맞 는지를 검사하여 이상이 없는 경우 Q_Process를 통하여 Q_Repository에 데이터를 임시 저장한다. 이렇게 임시 저장 된 데이터는 Q_Repository에서 보관되어지고 있다가 이를 항상 감시하고 있는 DB_Recorder에 의해 즉각적으로 데이 터베이스에 기록 작업을 수행하게 된다.

\section{2 다중 거주자 위치 추적서비스모델}

다중 거주자 위치 추적서비스모델은 기능별 모듈화 하였 으며 비교적 가벼운 GUI 처리 부분들은 단순 프로시저 형 태로 작성하여 필요시 각 기능별로 처리하는 데 사용될 수 있도록 하였다. MRTSM을 구성하는 요소들은 Fig. 6과 같 이 각각의 기능들은 다음과 같다.

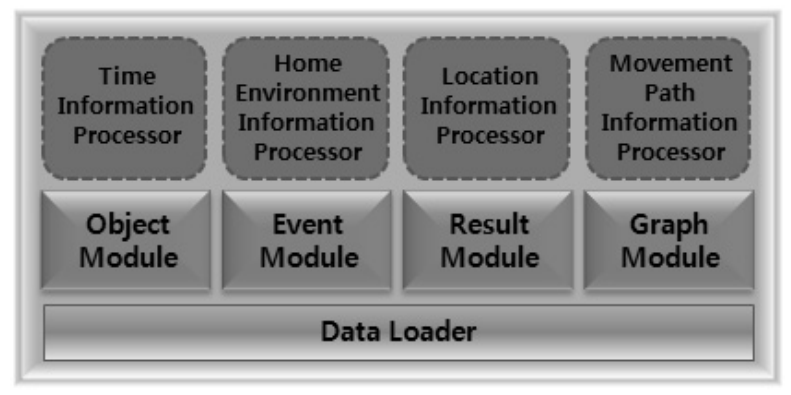

Fig. 6. Multi Resident Tracking Service Model(MRTSM)

- Data Loader : 하위레벨도구인 디바이스 매니저로부터 저장되는 데이터를 보관하는 저장소와 본 시스템을 이용하는 거주자의 프로파일(Profile)을 보관하는 저장소 그리고 위치 추 적 결과를 보관할 저장소인 Database로의 연결을 담당하며 이 후 GUI로부터 등록된 거주자의 프로파일과 Device Manager 로부터 저장된 데이터를 가져오는 기능을 담당한다.

- Object Module : Data Loader로부터 가져온 거주자의 프로파일을 관리하는 기능을 담당한다. 본 모듈은 거주자의 프로파일을 요구하는 다른 모듈로부터 사용된다.

- Event Module : 이벤트와 관련된 모든 기능을 담당한 다. 먼저, 주어진 복합 이벤트를 분석하여 하나의 복합 이벤 트에 담긴 한 명 이상의 거주자 수를 추출한다. 두 번째, 복 합 이벤트로부터 거주자가 현재 위치하는 장소를 추출한다. 세 번째, 복합 이벤트로부터 거주자가 사용 중인 사용도구 들을 추출한다. 네 번째, 복합 이벤트로부터 거주자에 의해 작동된 기타사항(도구 이외의 무게, 키, 조도로부터의 등 $\mathrm{On} / \mathrm{Off}$ )들을 추출한다. 다섯 번째, 복합 이벤트로부터 상황
을 분석한다. 여섯 번째, 복합 이벤트로부터 거주자를 분석 한다. 이때 거주자는 식별되지 않은 예상되는 거주자를 의 미한다. 일곱 번째, 복합 이벤트로부터 가중치를 얻는다. 여 덟 번째, 복합 이벤트로부터 거주자의 식별 유무(식별 여부) 를 판별한다. 마지막으로 복합 이벤트로부터 거주자의 수를 추출한 결과 한 명 이상인 경우 복합이벤트를 거주자의 수 에 맞게 분리한다.

- Result Module : 결과를 얻기 위한 기능과 결과를 기 록하는 기능을 주로 담당한다. 먼저 Event Module에서 얻 어진 임시적인 결과 즉, 식별되지 않은 가거주자의 상황 정 보를 비롯한 추출된 정보를 큐 저장소에 보관하며 이를 이 용하여 실제 거주자를 식별하고 그 결과 정보를 Database에 기록한다. 또한, 본 모듈에는 거주자를 식별하기 위해 필요 한 누적치를 구하는 기능을 포함한다.

- Graph Module : 식별된 거주자의 정보가 기록되어 있 는 Database로부터 가장 최근의 정보를 가져와 그래프 데이 터로 추가 등록한다.

- Time Information Processor : 클라이언트로 현재 시 간정보를 나타내기 위한 기능을 담당한다.

- Home Environment Information Processor : 클라이언 트로 실내환경센서에 의해 수집되어 Database에 저장된 온 도, 조도, 습도 정보를 나타내기 위한 기능을 담당한다.

- Location Information Processor : 복합 이벤트를 분석 하여 얻어진 거주자의 위치를 클라이언트로 나타내기 위한 기능을 담당한다.

- Movement Path Information Processor : 클라이언트 로 식별된 거주자의 정보를 그래프를 통해 실시간으로 나타 내기 위한 기능을 담당한다.

Fig. 7과 같이 데이터베이스에는 기존에 이미 식별된 데 이터들과 식별되어야 할 가장 최근 데이터가 존재한다. 데 이터는 실내 환경 정보를 포함하여 복합이벤트로 구성되고, 이를 분석한 거주자의 식별에 중점을 둔다.

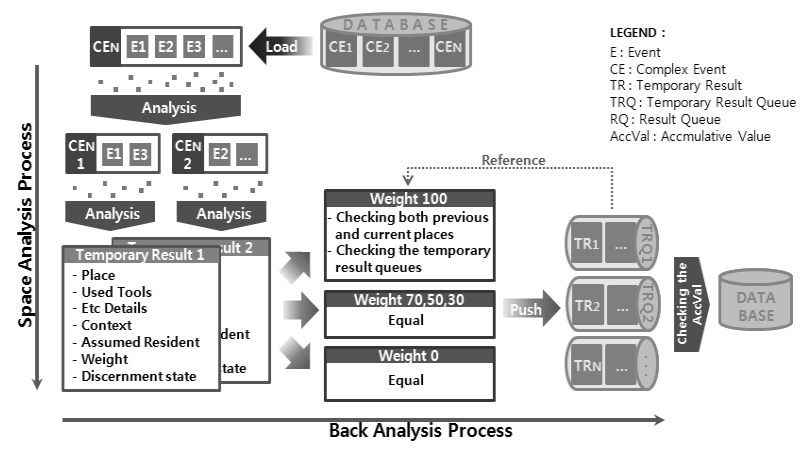

Fig. 7. The entire process of identifying residents

거주자를 식별하는 전반적인 과정은 앞서 $\mathrm{SABA}$ 메커니즘 설명을 통해 보인 것처럼 두 가지 방식의 분석 과정을 거쳐 이루어진다. 첫 번째는 공간 분석이다. 복합이벤트는 거주자 가 위치한 장소에 존재하는 센서들이 거주자의 행위에 반응 한 결과이기 때문에 실내 공간별로 복합된 이벤트들을 분석 하는 방법을 택하였다. 다중 거주자 위치 추적서비스모델은 데이터베이스에 기록된 복합이벤트 중 식별되지 않은 가장 
최근 데이터인 $\mathrm{CE}_{\mathrm{N}}$ 을 읽어와 $\mathrm{SABA}$ 메커니즘 분석방법에 따라 분석을 시작한다. 이때 복합이벤트는 단일 거주자의 행위에 의한 이벤트들로만 구성되어 있을 수도 있으며 다중 거주자의 행위에 의한 이벤트들로 구성되어 있을 수도 있기 때문에 먼저 해당 복합이벤트 $\left(\mathrm{CE}_{N}\right)$ 를 분석하여 몇 명의 거 주자에 의해 발생한 이벤트들인지를 알아야 한다. 복합이벤 트에서 존재하는 거주자의 수가 구해지면 그 수에 맞게 복 합이벤트를 분리시킨다. 분리된 복합이벤트는 거주자 개개 인을 식별하기 위해 다시 한 번 분석 과정을 거치며 이벤트 가 발생한 장소, 사용된 도구들, 기타 사항들, 거주자의 상 황, 예상되는 거주자, 가중치, 식별 상태 등의 임시 결과 (TR)들을 얻어낸다.

다중 거주자 위치 추적서비스모델의 GUI는 현재 추적되 고 있는 거주자의 정보를 모니터링 하도록 하였다. GUI 부 분은 Fig. 8과 같으며 크게 3영역으로 나누어져 있다. 가장 상단은 텍스트형태의 정보를 제공하는 영역으로 분리하여 이벤트가 발생한 시간과 수집된 실내 온도, 조도, 습도 정보 를 표시한다. 다음으로 가운데 영역은 실내 공간을 그대로 매핑한 이미지 상에 영역별 현제 거주자의 위치를 사람 이 미지로 나타내도록 하였고 거주자의 행위에 의해 사용이 감 지된 도구 또는 센서의 위치를 붉은색의 빈 박스 형태로 표 시하도록 하였다. 마지막으로 하단에는 앞서 설명한 식별과 정시의 문제를 해결하기 위해 구성하였으며 이를 위해 그래 프 모듈을 따로 작성하여 표시되도록 하였다. 그래프는 $\mathrm{y}$ 축 값으로 각 실내 공간별 이름을 표시하며 $\mathrm{x}$ 축 값으로 이벤트 가 발생한 시간을 표시한다. 그리고 추적되고 있는 거주자 의 위치 및 이동 경로를 각각의 다른 색으로 구분된 선을 통해 거주자가 식별된 공간까지 출력하였다.

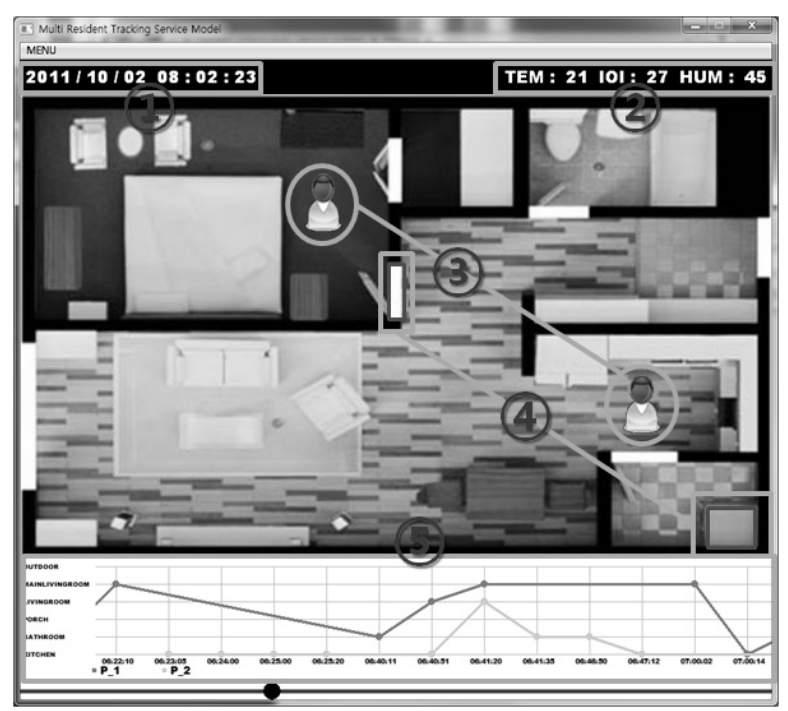

Fig. 8. The main GUI configuration

(1)은 거주자를 추적 중인 현재 날짜와 시간 정보를 나타 내며 (2)는 실내 온도, 조도, 습도 정보를 나타낸다. (3)은 이 벤트가 발생한 공간상에 거주자가 있음을 보여준다. (4)는 이벤트 분석결과 사용 중인 문이나 가전기기, 가구 등을 표 현한 것이다. (5)는 본 연구의 위치추적 메커니즘에 의해 추 적되어진 거주자의 공간별 위치 및 이동 상황을 실시간으
로 보이는 그래프이다. 본 그래프가 그려지는 과정은 거주 자의 이벤트 처리결과 식별되는 시점을 기준으로 다시 출 력한다.

\section{5. 다중 거주자 위치 추적 서비스의 수행 평가}

본 장에서는 지금까지 설명한 연구를 바탕으로 구현한 응 용과 응용 수행에 사용된 시나리오를 통해 본 위치 추적 시 스템의 수행성을 검증한다.

\section{1 수행평가를 위한 시나리오}

시나리오를 위해 응용을 통해 등록되는 거주자 프로파일 은 Table 6과 같으며 응용상에 기본 값으로 정의된 식사 및 주방일 시간은 Table 7과 같다. 시나리오 상에서 거주자의 수는 두 명으로 하였으며 서로 간에 구분을 명확하게 구 분하기 위해 각 항목들은 동일한 값의 사용을 피하도록 하였다.

Table 6. Residents Profile

\begin{tabular}{c|c|c|c}
\hline \multicolumn{2}{|c|}{ 거주자 1 } & \multicolumn{2}{c}{ 거주자 2} \\
\hline 이름 & Man & 이름 & Woman \\
\hline 나이 & 60 & 나이 & 55 \\
\hline 무게 & 65 & 무게 & 54 \\
\hline 키 & 170 & 키 & 160 \\
\hline 성별 & 남 & 성별 & 여 \\
\hline 역할 & 외업 & 역할 & 가사 \\
\hline 선호자리(소파) & 좌측 & 선호자리(소파) & 우측 \\
\hline 선호자리(식탁의자) & 좌측 & 선호자리(식탁의자) & 우측 \\
\hline 취침시간 & $22: 30 ~ 06: 20$ & 취침시간 & $23: 00 ~ 06: 20$ \\
\hline 외업시간 & $08: 00 ~ 18: 30$ & 외업시간 & Null \\
\hline 낮잠시간 & Null & 낮잠시간 & $14: 00 ~ 15: 00$ \\
\hline 아침세면시간 & $06: 25 ~ 06: 50$ & 아침세면시간 & Null \\
\hline 여가시간 & Null & 여가시간 & $10: 30 ~ 12: 30$ \\
\hline
\end{tabular}

Table 7. Dining and kitchen during the day time

\begin{tabular}{c|c}
\hline 상황 & 시간 \\
\hline 아침식사 & $07: 00 \sim 07: 30$ \\
\hline 점심식사 & $12: 30 \sim 13: 00$ \\
\hline 저녁식사 & $19: 30 \sim 20: 00$ \\
\hline 주 방 일 & 식사 전 · 후 20분 \\
\hline
\end{tabular}

시나리오 배경은 주방에서 'Woman'이 아침식사를 준비하 는 동안 안방에서 옷을 갈아입던 'Man'이 아침식사를 위해 주방으로 간다. 함께 식사를 하는 중에 'Man'이 먼저 식사 를 마치고 화장실을 이용한다. 다시 거실로 이동 후 두 명 의 거주자가 소파에서 짧은 휴식을 취한다.

본 시나리오를 기반으로 수행된 다중 거주자 위치 추적 서비스 모델은 두 명의 거주자가 서로 다른 장소에서 한곳 으로 모였을 때 식별되는 과정 및 분리 시 식별되는 과정을 모두 확인하였다. 시나리오를 기반으로 발생할 수 있는 문 
제점은 주방의 경우 문이 존재하지 않아 다른 장소로 이동 또는 다른 장소에서 주방으로 이동한 경우 이동 상황으로 처리되지 않아 이동 및 장소에 의한 연관성을 찾을 수 없어 복합이벤트가 완전히 일치하지 않음을 알 수 있다. 하지만 거주자 식별이 한 장소 또는 하나 이상의 장소를 거쳐 식별 되고 있음을 확인하였으며 본 연구에서 사용한 다양한 식별 방법이 각각의 상황에 사용되어 개별 거주자를 식별하고 그 위치를 추적할 수 있음을 시나리오 수행 과정을 통해 확인 하였다.

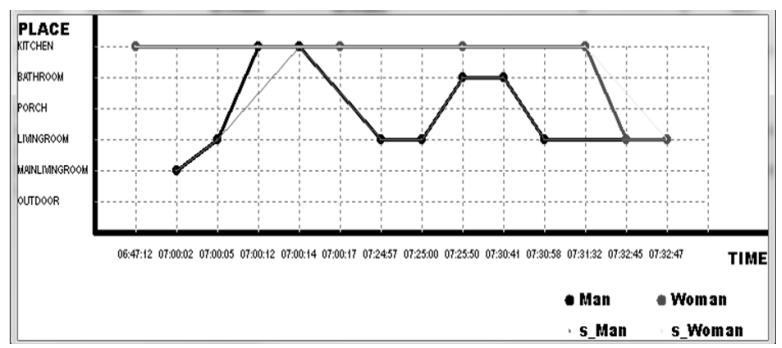

Fig. 9. Residents identified the overall result

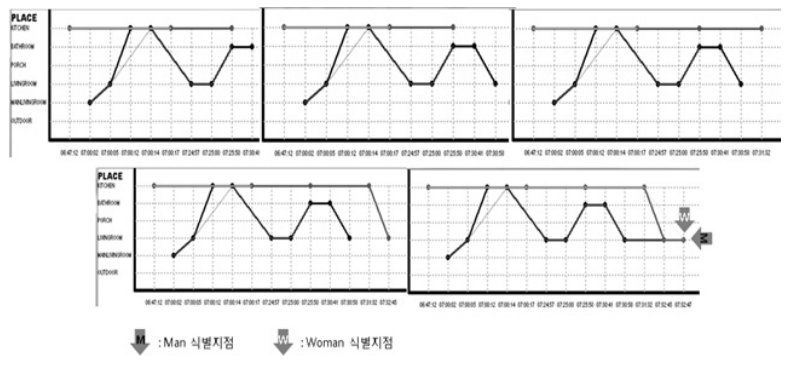

Fig. 10. A step-by-step process of identifying residents

\section{2 결과 분석}

시나리오를 기반으로 하루 중 발생한 복합이벤트를 수행 한 결과를 분석한 내용을 기술하고 분석한 내용을 토대로 종합하여 원인 및 해결방안을 제시한다.

다음 Table 8은 시나리오 수행 결과를 토대로 세 종류의 복합이벤트로 분리하여 정리한 결과이다.

Table 8. Results by residents of the complex event

(단위 : 복합이벤트 개수)

\begin{tabular}{c|c|c|c}
\hline 거주자 & $\begin{array}{c}\text { 시나리오 } \\
\text { 복합이벤트 }\end{array}$ & $\begin{array}{c}\text { 식별된 } \\
\text { 복합이벤트 }\end{array}$ & $\begin{array}{c}\text { 일치된 } \\
\text { 복합이벤트 }\end{array}$ \\
\hline 전체 & 115 & 94 & 76 \\
\hline Man & 38 & 37 & 24 \\
\hline Woman & 77 & 57 & 52 \\
\hline
\end{tabular}

시나리오 복합이벤트는 하루 중 발생한 복합이벤트를 의 미하며 식별된 복합이벤트는 시나리오 수행 후 얻은 결과에 서 등록된 거주자 중 어느 한 명으로 식별된 복합이벤트를 의미한다. 그리고 일치된 복합이벤트는 식별된 복합이벤트 중에서 시나리오 복합이벤트와 동일한 시간대 거주자와 일 치하는 복합이벤트를 의미한다.

Table 8을 이용하여 얻어진 복합이벤트의 일치율을 분석
한 결과 본 시스템의 전체적인 거주자 식별 능력(시나리오 복합이벤트와 일치된 복합이벤트에 대한 비)은 $66 \%$ 의 수치 를 보였으며 복합이벤트 분석 중 소실된 복합이벤트를 제외 한 식별된 복합이벤트 중에서만 볼땐 $81 \%$ 의 식별 능력을 보 였다.

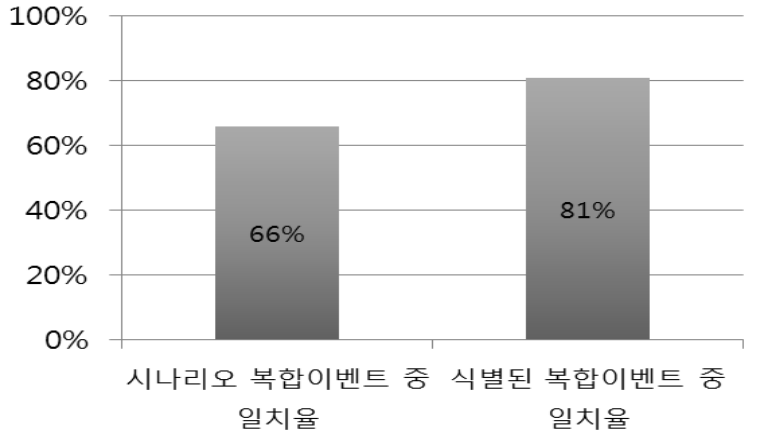

(Fig. 11A)

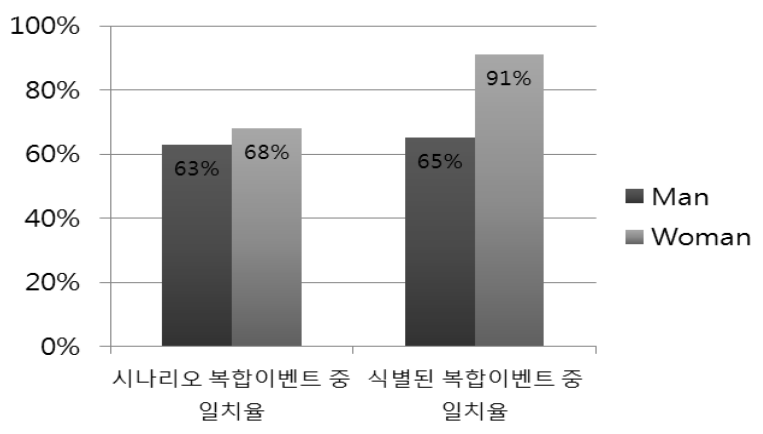

(Fig. 11B)

Fig. 11. Complex Event concordance of full (A) and the residents(B)

거주자별로 볼 땐 가사역할을 담당하는 Woman의 식별 능력이 전체적으로 높게 나타났으며 식별된 복합이벤트 중 에서 비교했을 때 $91 \%$ 로 다른 수치에 비해 비교적 높은 수 치를 보여주기도 하였다. 이러한 결과로 거주자에 따라 식 별 능력의 차이가 있음을 알 수 있다.

공간별로 발생한 복합이벤트의 개수는 시나리오 복합이벤 트 상에서 볼 때 거실에서 가장 많이 발생하였으며 다음으 로 주방, 화장실, 안방, 현관, 그리고 실외 순으로 나타났다. 여기서 실외는 본 논문에서 정의한 실내구성상의 공간이 아 닌 현관 밖을 의미하며 거주자가 외출 후 실내로 들어올 때 의 상황으로써 하나의 공간으로 본다.

다음 Fig. 12는 공간별로 분석된 복합이벤트의 일치율을 보이고 있으며 여기서 점선은 시나리오 복합이벤트에 대한 일치된 복합이벤트의 비이며 직선은 식별된 복합이벤트에 대한 일치된 복합이벤트의 비를 나타낸다.

전체적으로 볼 때 실외에서 두 부분의 일치율 모두 $100 \%$ 의 수치를 보여 가장 높은 식별률을 보였고 다음으로 현관 은 시나리오 복합이벤트 중에 소실이 발생하여 시나리오 복 합이벤트에 대한 비율은 $100 \%$ 에 약간 미치지 못하나 식별 된 복합이벤트에 대한 비율에서는 $100 \%$ 를 보여 실외와 거 의 같은 수준의 식별률을 보였다. 다음으로 주방에서의 일 


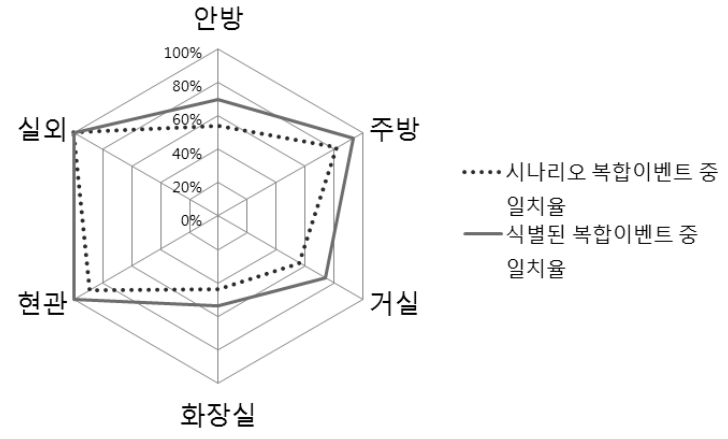

Fig. 12. The space complex event-specific concordance

치율이 각각 $82 \%$ 와 $93 \%$ 로 비교적 높은 수치의 식별률을 보였다. 다음으로 일치율 $80 \%$ 이하로 나타난 거실, 안방, 화 장실 순으로 식별률을 보였다.

소실은 복합이벤트 분석이 끝나고 분석된 내용으로 역분 석 과정을 수행 중에 이전의 분석결과들과 비교하는 과정에 서 연관성을 전혀 찾지 못한 경우 임시결과큐에 저장되지 못하고 단지 비교 과정으로 끝나는 것을 의미하며 이렇게 소실되는 복합이벤트는 더 이상의 분석 과정에서 제외된다. Fig. 13은 각종 소실율을 분석한 결과를 보이고 있다.

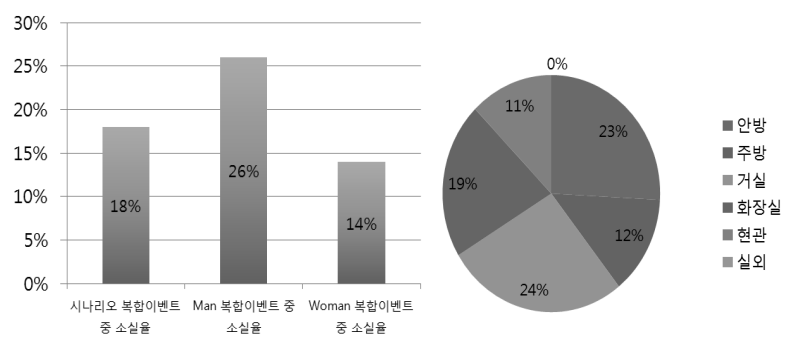

Fig. 13. Total and per resident (left) and space-specific (right) complex event dissipation

본 시나리오 상에서 시스템 전체적으로 나타난 복합이벤트 의 소실율은 $18 \%$ 로 나타났으며 거주자별로 볼 때 역할이 외 업인 Man 거주자의 경우 가사인 Woman 거주자에 비해 다 소 높은 수치를 보이고 있음을 알 수 있다. 공간별로 확인해 볼 때 거실에서의 소실율이 가장 높게 나타났으며 다음으로 안방, 화장실, 주방, 현관, 실외 순으로 소실율을 보이고 있다.

본 논문에서 제안한 다중 거주자 위치 추적 서비스모델의 신뢰도를 높이기 위해서는 다음과 같은 해결 방안이 요구된다.

첫 번째, 본 시스템의 거주자 식별 능력은 거주자의 역할 이 가장 큰 요소로 작용하고 있음을 알 수 있다.

두 번째, 화장실에 배치된 무게감지센서의 역할이 너무 기대 이하로 나타나 센서 배치면에서 보다 효율적인 위치 사용이 요구된다.

세 번째, 실내 구조에서 볼 때 거실에서 현관으로 이동하 는 경우와 주방으로 이동하는 경우 또는 반대의 경우 문이 없어 복합이벤트 분석 시 이동 상황으로 상황인식이 잘되지 않는 문제점이 발생하여 이전 장소 비교에 의한 식별률이 떨어진다. 이를 해결하기 위한 이동에 대한 상황 인식의 기
준 추가나 개선이 요구된다.

네 번째, 다소 낮은 시스템의 식별 능력은 저비용을 의식 한 너무 적은 실내 도구의 사용 제한에 기인하므로 비용대 비 실내 도구나 센서 사용을 시스템 설계 시 고려하여 최적 의 식별률 대비 비용을 미리 알아볼 필요가 있다.

\section{6. 결 론}

국내외 실내 위치추적에 관련된 연구가 유비쿼터스 홈 환경을 기반으로 활발하게 진행되고 있다. 본 논문에서는 3 가지를 이슈를 고려하여 시스템을 제안하였다. 첫째, 무구 속 및 무자각을 지향하는 시스템 환경을 구성하고, 둘째로 저비용의 시스템을 구현, 셋째로 다수의 거주자를 수용할 수 있도록 하고자 하였다. 이를 위해 사용되는 센서로는 무 구속 및 무자각할 수 있는 센서들만을 선별하도록 하였으 며 그 중에서 저가의 가벼운 센서를 이용하여 각 위치에 설정하도록 하였고, 다중 거주자의 행위에 의해 발생하는 수많은 이벤트들을 분석하여 개인을 식별할 수 있는 메커 니즘을 설계하여 검증을 위해 본 논문의 응용 서비스에 적 용하였다. 그리고 수행된 응용에 나타난 시간별 활동 중인 공간을 나타내는 그래프를 통해 실제로 한 명 이상의 거주 자가 이벤트가 발생한 시점에서 각각 분리되어 나타나 있 음을 통해 메커니즘이 목적에 맞게 동작하는 수행성을 검 증하였다.

향후연구로는 제안한 다중거주자의 식별방법은 $80 \%$ 의 정확성을 가졌으나 나머지 $20 \%$ 에 해당하는 실생활의 패턴 들을 찾아내기 위한 연구가 요구된다. 그리고 현재 제한된 조건과 시나리오를 통해 다중 거주자 추적을 위한 성능을 평가하였으나 실제 홈 환경에서 성능평가 연구를 진행하고 자 한다.

\section{Reference}

[1] Kevin Currana, Eoghan Fureya, Tom Lunneya, Jose Santosa, Derek Woodsa \& Aiden McCaugheya, "An evaluation of indoor location determination technologies," Journal of Location Based Services, Vol.5, Issue 2, pp.61-78, 2011.

[2] Chao Chen, Daqing Zhang, Lin Sun, Mossaab Hariz, Yang Yuan, "Dose Location Help Daily Activity Recognition," Impact Analysis of Solutions for Chronic Disease Prevention and Management LNCS Vol.7251, pp.83-90, 2012.

[3] Chang Won Jeong, Young Sik Jeong, Su Chong Joo, "Indoor Location Tracking Service Based on u-Home Environments," Embedded and Multimedia Computing Technology and Service LNEE Vol.181, pp.55-62, 2012.

[4] H. Y. Lee, "Improving livelihood of the elderly through utilizing Ubiquitous technology”, pp.56-67, 2007.5.

[5] Soomi Park, "A Study on the Gender Gap in the Korean Elderly Women's Time Use,” The Women's Studies, Vol.72 No.1, pp.5-30, 2007.

[6] Ahmad CHOUKEIR, Batoul FNEISH, Nour ZAAROUR, Walid FAHS, Mohammad AYACHE, "Health Smart Home," IJCSI International Journal of Computer Science Issues, Vol.7, Issue 6, pp.126-130, November, 2010. 
[7] Xuan Hoa Binh Le, Maria Di Mascolo, Alexia Gouin, and Norbert Noury, "Health Smart Home-Towards an assistant tool for automatic assessment of the dependence of elders," Proceedings of the 29th Annual International Conference of the IEEE EMBS Cité Internationale, Lyon, France August, 23-26, 2007.

[8] Gyeyoung Lee and Jaegeol Yim, "A Review of the Techniques for Indoor Location based Service," International Journal of Grid and Distributed Computing, Vol.5, No.1, March, 2012.

[9] P. Klasnja, S. Consolvo, T. Choudhury, R. Beckwith, and J. Hightower, "Exploring privacy concerns about personal sensing", Lecture Notes in Computer Science, Volume. 5538/2009, pp176-183, May, 2009.

[10] G. Shakhnarovich, L. Lee, T. Darrell, "Integrated face and gait recognition from multiple views", Conference on Computer Vision and Pattern Recognition, IEEE Computer Society Conference, Vol.1, pp.439-446, 2001.

[11] D. H. Wilson, C. Atkeson, "Simultaneous tracking and activity recognition (STAR) using many anonymous, binary sensors", Lecture Notes in Computer Science, Vol.3468, pp.329-334, 2005.

[12] J. Jenkins, C. Ellis, "Using ground reaction forces from gait analysis: body mass as a weak biometric", Lecture Notes in Computer Science, Vol.4480, pp.251-267, 2007.

[13] C. BenAbdelkader, R. Cutler, L. Davis, "Person identification using automatic height and stride estimation", International Conference on Pattern Recognition, Vol.4, pp.377-380, 2002.

[14] Y. Nishida, S. Murakami, T. Hori, H. Mizoguchi, "Minimally privacy-violative human location sensor by ultrasonic radar embedded on ceiling", Proceedings of IEEE, Vol.1, pp. 433-436, Oct., 2004.

[15] C. J. Jenkins, "The weakly identifying system for doorway monitoring", Dissertation submitted in partial fulfillment of the requirements for the degree of Doctor of Philosophy in the Department of Computer Science in the Graduate School of Duke University, 2007.

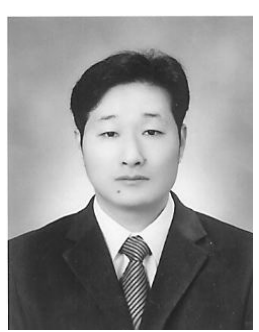

\section{정 창 원}

e-mail :mediblue@wku.ac.kr

1993년 2월 원광대학교 컴퓨터공학과(학사)

1998년 8월 원광대학교 컴퓨터공학과(석사)

2003년 2월 원광대학교 컴퓨터공학과(박사)

2004년 2006년 전북대학교 학술연구교수

2006년 2013년 원광대학교 전기전자 및

정보공학부 Post.Doc

2013년 현 재 원광대학교 리서치펠로우 연구교수

관심분야: Distributed Computing, Ubiquitous Computing,

Multimedia Service, LBS. U-healthcare,

Medical Information System

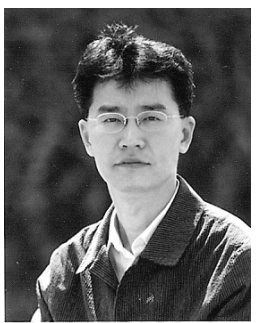

고 광 만

e-mail : kwangman.ko@gmail.com

1991년 2월 원광대학교 컴퓨터공학과 (공학사)

1993년 2월 동국대학교 컴퓨터공학과 (공학석사)

1998년 2월 동국대학교 컴퓨터공학과 (공학박사)

1998년 3월 2001년 8월 광주여자대학교 컴퓨터과학과 전임강사 2001년 9월 현 재 상지대학교 컴퓨터정보공학부 교수 관심분야: Energy-aware Compiler Technology, Eco-Mobile Computing

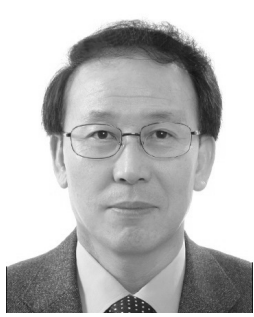

\section{주 수 종}

e-mail :scjoo@wku.ac.kr

1986년 원광대학교 전자계산공학과(학사)

1988년 중앙대학교 컴퓨터공학과(공학석사)

1992년 중앙대학교 컴퓨터공학과(공학박사)

1993년 미국 University of Massachusetts at Amherst, Post-Doc.

2003년 미국 University of California at Irvine, Visiting Professor

2007년 2009년 원광대학교 정보전산원 원장

1990년 현 재 원광대학교 컴퓨터공학과 교수

2013년 현 재 원광대학교 BK 플러스, ICT기반 라이프케어 융·복합 인재양성사업단, 병원특성화연구센터

관심분야: Distributed Real Time Computing, Distributed Object Model, System Optimization, u-home Service, $\mathrm{u}$-healthcare 